\title{
Discovery of itacolumites in the central highlands of Madagascar
}

\author{
Hiroyuki SuzuKI", Yasumitsu KanIE**, Yuki KanIE**, \\ Roger A. RAMBELOSON ${ }^{* * *}$ and Voahangy RAMASIARINORO ${ }^{* * *}$ \\ "Murasakino-miyanishi-cho 10-4, Kita-ku, Kyoto 603-8158, Japan \\ ${ }^{* *}$ Numama 2-9-4-405, Zushi 249-0004, Japan \\ ${ }^{* * *}$ Department des Sciences de la Terre, Faculite des Sciences, \\ Universite d'Antananarivo, B.P.906, Antananarivo 101, Madagascar
}

\begin{abstract}
The presence of itacolumites, or flexible quartzites, and the precise geological descriptions of the same have hitherto been reported only in India, Brazil, and the Appalachian region of the USA. In this paper, we report the discovery of itacolumites from three localities in the central highlands of Madagascar. The localities are underlain by the Mesoproterozoic Itremo Group. The occurrence and petrography of these itacolumites and the results of SEM observations are summarized in this paper. The itacolumites from Madagascar contain very coarse grained one beside the fine-to-medium-grained varieties that are common to India, Brazil, and the Appalachians. Furthermore, the itacolumites of Madagascar occur over a wide area of exposure, supporting the opinion that their formation was a result of chemical weathering.
\end{abstract}

Keywords: Itacolumites, Quartzites, Petrography, Flexibility, Proterozoic, Madagascar

\section{INTRODUCTION}

Itacolumites are quartzites that exhibit remarkable flexibility when split into thin slabs (Bate and Jackson, 1987). The name "itacolumite" is derived from Mt. Itacolomi near the city of Ouro Preto in Minas Gerais, Brazil, where itacolumites were first described in the $18^{\text {th }}$ century (Shepard, 1845). Itacolumites have been found in Proterozoic quartzites of Brazil, India, and the Appalachian region of the USA (Wadia, 1961; Oliveira, 1956; Bennison, 1989). Specimens of itacolumites from these three countries can be easily obtained from shops selling geological specimens in Japan. Reports of itacolumites from France (Ginsburg and Lucas, 1949) and China (Kerbey, 2011) lack the precise geologic description of outcrops.

In Brazil, India, and the Appalachians, itacolumites are found only in restricted parts of a quarry of massive nonflexible rigid quartzites that are excavated and used as construction materials (Suzuki and Shimizu, 1993; Kerbey, 2011).

On the basis of mineral composition, grain size, preferred orientation analysis of thin sections (under a microscope), and the scanning electron microscope (SEM) observation of fractured and grain surfaces, Indian

doi:10.2465/jmps. 101210

H. Suzuki, kbbhh761@ybb.ne.jp Corresponding author itacolumites have been identified as sedimentary quartzites (mature quartzose sandstone), whereas Brazilian and Appalachian itacolumites have properties that correspond to those of metamorphic quartzites (micaceous schistose quartzites) (Suzuki and Shimizu, 1993).

The flexibility of itacolumites originates from their peculiar fabric: although the quartz grains are irregularly shaped and well interlocked, they are separated from each other by uniformly- narrow intergranular voids (Wetherill, 1867). The existence of such intergranular voids has been ascertained by microscopic observation, SEM studies, and acoustic emission studies (Suzuki et al., 1993).

The porosities of itacolumites have been measured to be $6 \%$ to $19 \%$ by the point-counting method and image analysis as well as by using a pycnometer. These values are twice or thrice those of nonflexible quartzites (Suzuki et al., 1993). The most important feature of the itacolumite fabric is not the total void space volume but the three-dimensional network of narrow intergranular voids throughout the rock mass. On the basis of the results obtained by SEM and acoustic emission studies, the itacolumite fabric is represented schematically by a jigsaw puzzle model. This model can also easily explain the reason for the flexibility and deformation of itacolumites (Suzuki et al., 1993).

The results of hydrothermal experiments carried out 


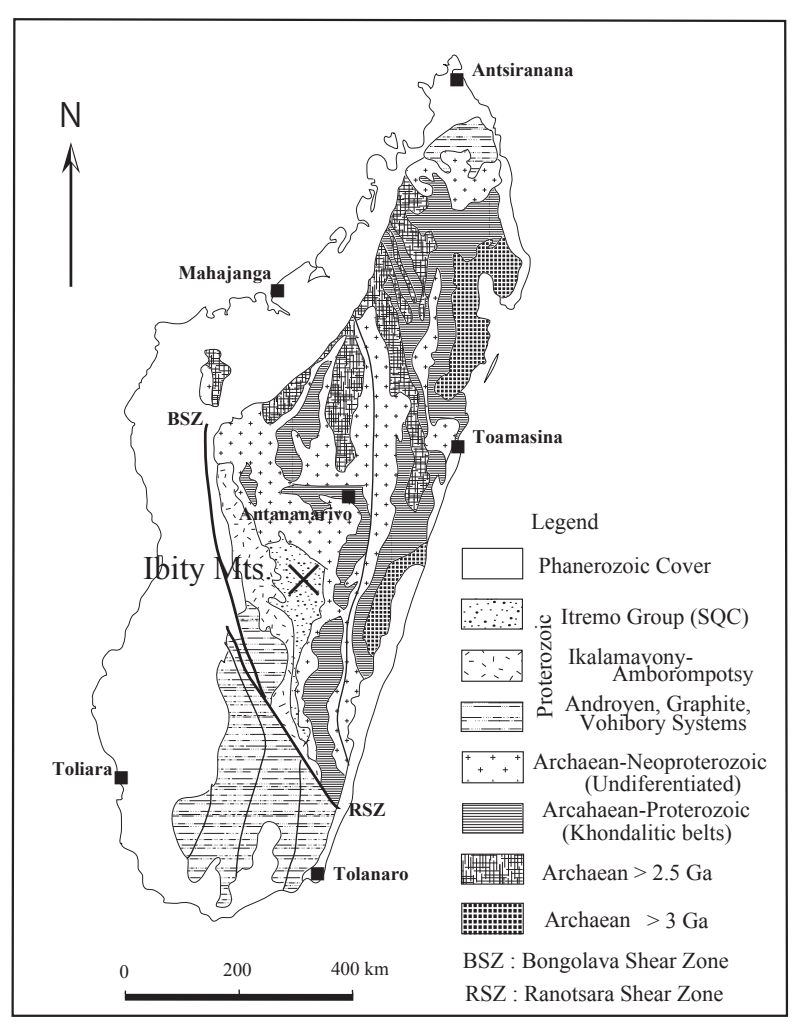

Figure 1. Precambrian geology of Madagascar (simplified after Rambeloson, 2004). The cross represents the location of the Ibity Mountains.

on nonflexible quartzites suggest that the uniformly-narrow intergranular voids of itacolumites are formed by the chemical dissolution of quartz at the grain boundaries of nonflexible quartzites during weathering at or near the earth's surface (Suzuki, 1996). However, the precise conditions during chemical weathering have not been well established because of the scarcity of outcrops.

Itacolumites, which are aggregates of a brittle material (quartz), have recently attracted the attention of material scientists because the jigsaw-puzzle-like itacolumite fabric can exhibit considerable flexibility in room temperature and at atmospheric pressure. The bending strength of itacolumites is so low that they cannot be used as industrial materials (Suzuki et al., 1993) such as construction materials. However, several materials science researchers, including those from Japan, are trying to invent "new materials" such as earthquake-resistant building materials (Yamaguchi et al., 2007), flexible ceramics (Sato et al., 2008), and new refractory materials (Dorcieux et al., 2008) by simulating the itacolumite fabric in stronger materials. Thus, itacolumites are unique from both scientific and industrial viewpoints, but their scarcity in nature has hindered the precise understanding of their origin.

In this study, we report our discovery of itacolumites in the central highlands of Madagascar, which will pro-

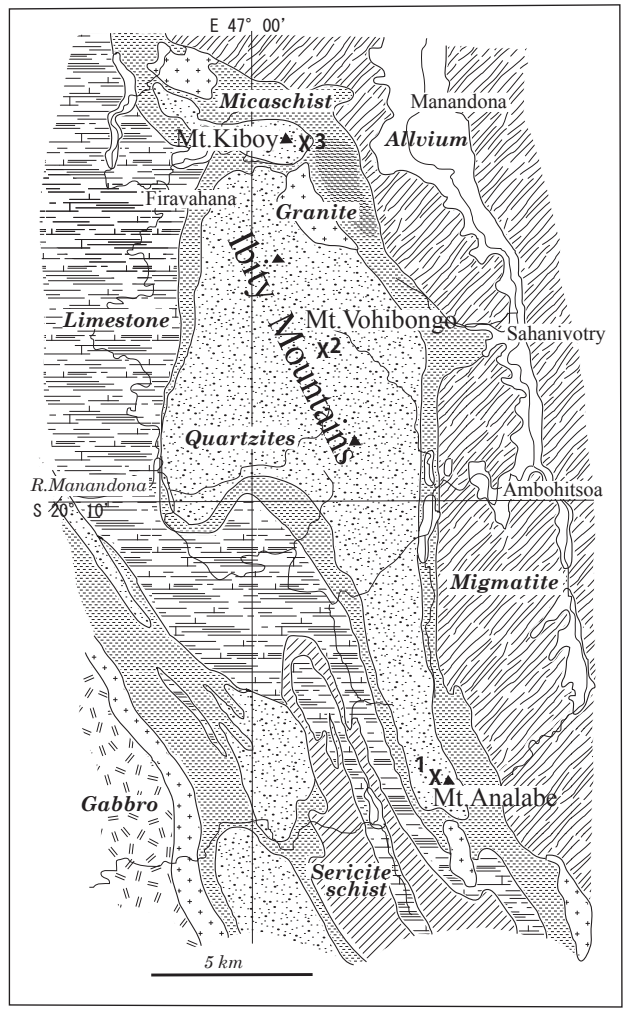

Figure 2. Geologic map around the Ibity Mountains (simplified after Service Geologique de Madagasikara, 1968) and itacolumite localities. 1, Analabe; 2, Vohibongo; 3, Kiboy.

vide new insights into their origin.

\section{NEW LOCALITIES OF ITACOLUMITES IN MADAGASCAR}

Itacolumites were discovered in three localities (Analabe, Vohibongo, and Kiboy) around the Ibity Mountains located about $140 \mathrm{~km}$ to the south of Antananarivo in the central highlands of Madagascar (Fig. 1).

The Analabe locality (Fig. 2) is located along a road cutting throughout the pass (1905 $\mathrm{m}$ above sea level) to the west of Mt. Analabe located to the south of the Ibity Mountains. The GPS coordinates of this pass are $\mathrm{S} 20^{\circ} 14^{\prime} 35^{\prime \prime}$ and $\mathrm{E} 47^{\circ} 03^{\prime} 09^{\prime \prime}$. This locality is underlain by a thick pile of interbedded quartzites and mica schist trending $\mathrm{N} 05-20^{\circ} \mathrm{E}$ and dipping steeply $\left(80^{\circ}\right)$ to the west. Quartzites are fine-to-medium-grained, and ripple marks are well preserved (Figs. 3a and 3b). Nearly all quartzites beds show some degree of flexibility and nonflexible quartzites are nearly absent.

The Vohibongo locality (Fig. 2) is a whetstone quarry (Fig. 3c) located to the west of Mt. Vohibongo in the central part of the Ibity Mountains. The GPS coordinates of this quarry are $\mathrm{S} 20^{\circ} 08^{\prime} 04^{\prime \prime}, \mathrm{E} 47^{\circ} 02^{\prime} 08^{\prime \prime}$, and the quarry 

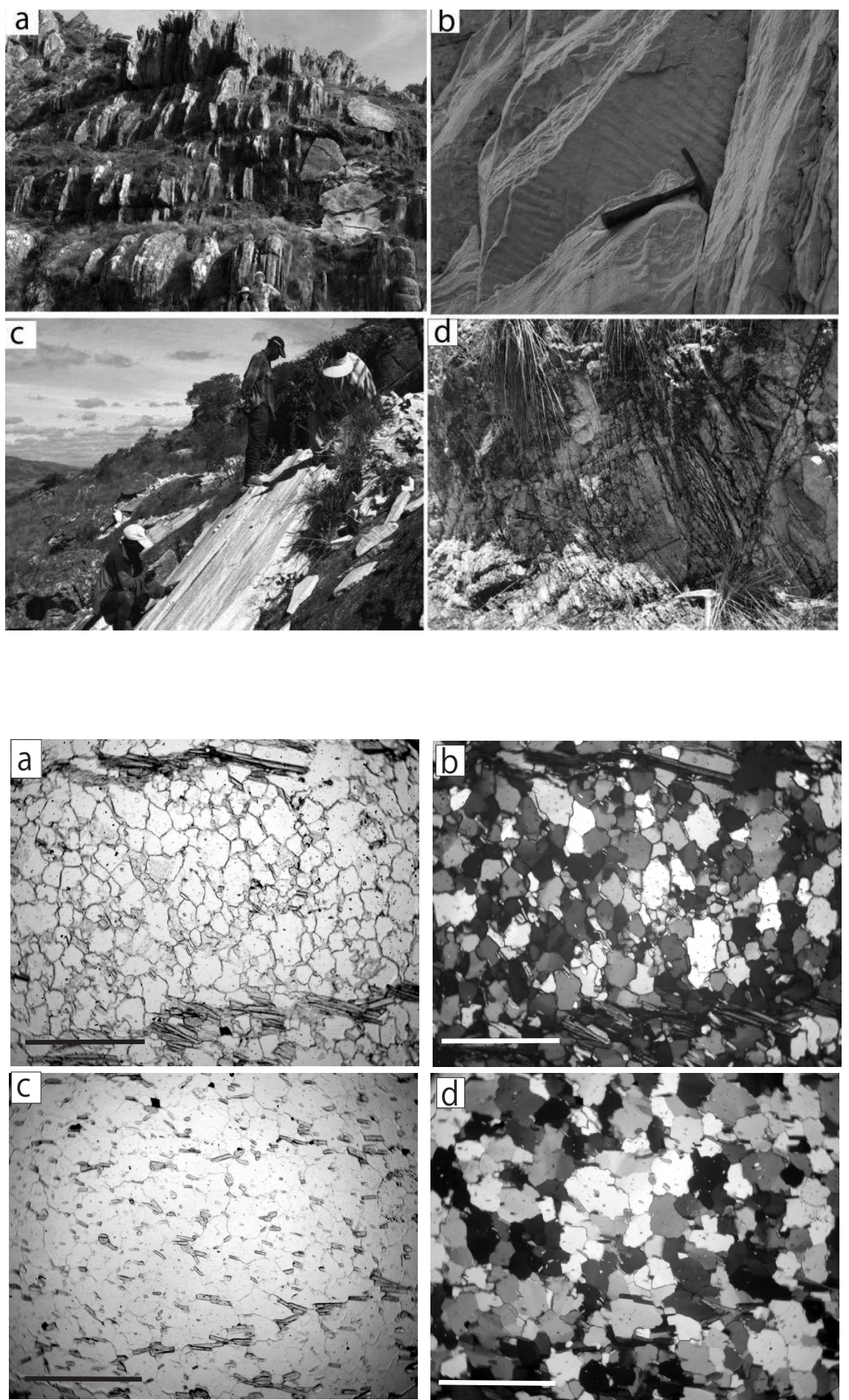

Figure 3. Places where itacolumites occur in Madagascar. (a) and (b) Analabe. (c) Vohibongo. (d) Kiboy.
Figure 4. Photomicrographs of thin sections of fine-grained itacolumites obtained from the Analabe locality using plane-polarized light (a) and cross polarized light (b), and those of nonflexible quartzites obtained from the same locality using plane-polarized light (c) and cross polarized light (d). Each scale bar is $1 \mathrm{~mm}$. is located about $1740 \mathrm{~m}$ above sea level. This locality is underlain by fine-to-medium-grained micaceous schistose quartzites. Itacolumites rarely occur along the schistosity plane, and if they do, they occur as thin layers sandwiched between two rigid nonflexible quartzite layers.

The Kiboy locality (Fig. 2) is located along a road cutting through the pass $(1610 \mathrm{~m}$ above sea level, $\left.\mathrm{S} 20^{\circ} 04^{\prime} 01^{\prime \prime}, \mathrm{E} 47^{\circ} 01^{\prime} 09^{\prime \prime}\right)$ off the eastern foot of Mt. Ki- boy located to the north of the Ibity Mountains. Along the road cutting, a thick pile of faintly bedded coarse-grained quartzites is outcropped, and almost all beds of quartzites have weathered into loosely packed masses of quartz grains. Itacolumites are rarely found in these beds, and further, it is very difficult to find nonflexible quartzites. Sedimentary structures such as cross bedding and ripple marks are well preserved (Fig. 3d). 

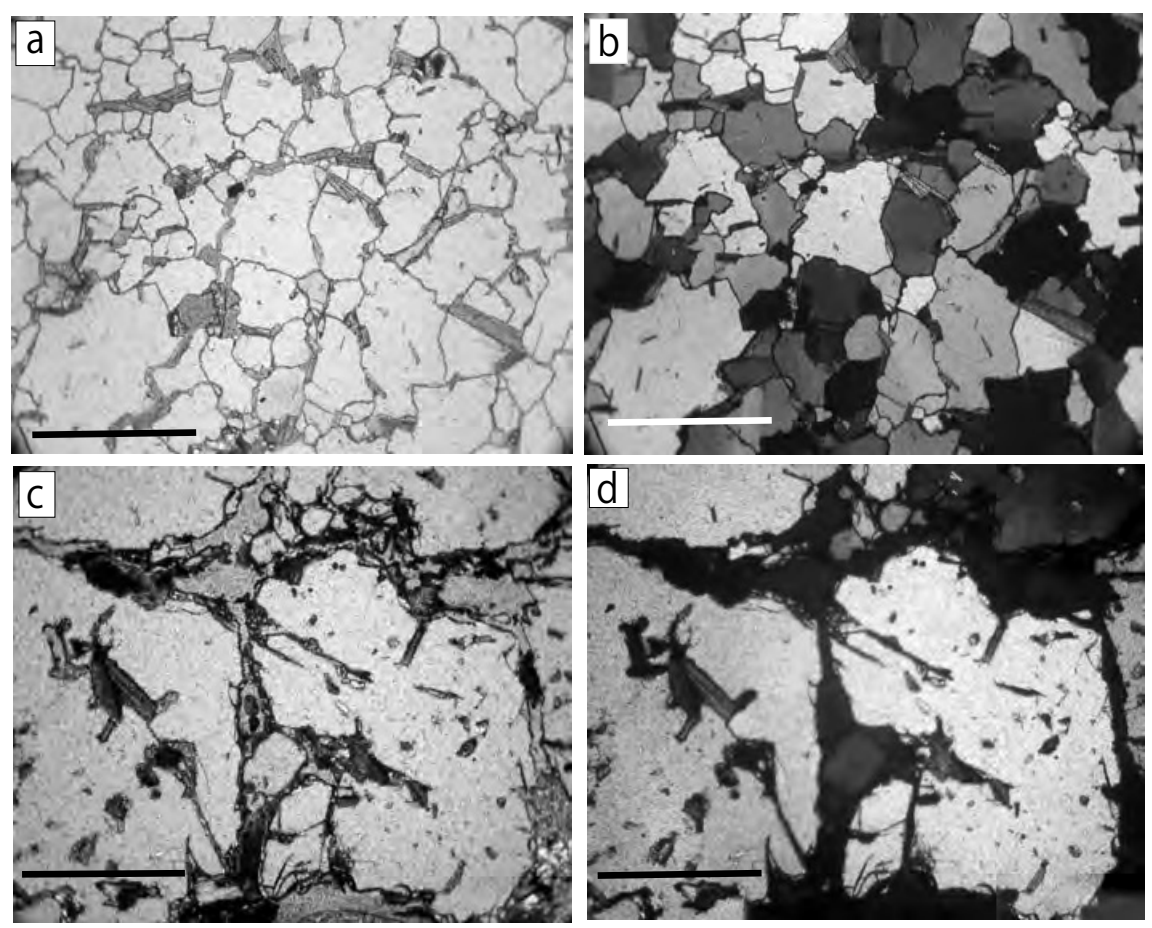

Figure 5. Photomicrographs of thin sections of medium-grained itacolumites obtained from the Vohibongo locality using plane-polarized light (a) and cross polarized light (b), and those of coarse-grained itacolumites of the Kiboy locality using plane-polarized light (c) and cross polarized light (d). Each scale bar is $1 \mathrm{~mm}$.

According to the geological map (scale 1/100000) of the quadrangle "Manandona" published by the Service Geologique de Madagasikara (1968), the three localities are underlain by quartzites of "ensemble schisto-quartzocalcaire (SQC)," whose geologic age is not mentioned (Fig. 2). In the recent literature, "ensemble SQC" has been referred to as the Itremo Group (Cox et al., 1998; Rambeloson, 2004; Tucker et al., 2007) (Fig. 1), which includes slates, biotite-muscovite schist, kyanite/sillimanite-bearing mica schist, quartzite that preserves ripple marks, and stromatolite-bearing dolomitic and/or calcite limestone (Rambeloson et al., 2003).

The Itremo Group, which forms a part of the Gondwanan metasedimentary belt of the East African Orogen, has been considered a passive margin sequence deposited largely during the Mesoproterozoic on a continental shelf or platform of the West Gondwana margin (Cox et al., 1998; Rambeloson et al., 2003; Collins et al., 2011). Late Neoproterozoic metamorphism is related to the final assembly of the Gondwana supercontinent (Tucker et al.,
2007; Santosh et al., 2009).

\section{PETROGRAPHY OF ITACOLUMITES FROM MADAGASCAR}

Photomicrographs of the thin sections of fine-grained itacolumites and nonflexible quartzites obtained from the Analabe locality are shown in Figure 4. Photomicrographs of thin sections of the medium-grained itacolumites collected from the Vohibongo locality and coarse-grained itacolumites obtained from the Kiboy locality are shown in Figure 5.

The mineral composition of the itacolumites and nonflexible quartzites collected from the three localities is determined by applying the point-counting method to a thin section. The results are shown in Table 1. The constituent minerals of the itacolumites and nonflexible quartzites are quartz $(70-80 \%)$ and muscovite $(5-15 \%)$. The muscovite content of the itacolumites is one-third to two-thirds of that of the nonflexible quartzites, while the

Table 1. Mineral composition and grain size of itacolumites and nonflexible quartzites obtained from Madagascar

\begin{tabular}{lcccccc}
\hline & \multicolumn{2}{c}{ Analabe } & \multicolumn{2}{c}{ Vohibongo } & \multicolumn{2}{c}{ Kiboy } \\
& Quartzite & Itacolumite & Quartzite & Itacolumite & Itacolumite 1 & Itacolumite 2 \\
\hline Quartz (\%) & 80.5 & 76.7 & 79.6 & 74.1 & 71.2 & 76.6 \\
Muscovite (\%) & 14.3 & 5.0 & 10.4 & 7.7 & 10.0 & 7.0 \\
Void (\%) & 5.0 & 18.3 & 9.7 & 18.1 & 18.8 & 16.5 \\
\hline Grain size (mm) & 0.18 & 0.20 & 0.42 & 0.45 & 1.18 & 1.23 \\
\hline
\end{tabular}

Nonflexible quartzite specimen could not be obtained from the Kiboy locality. 

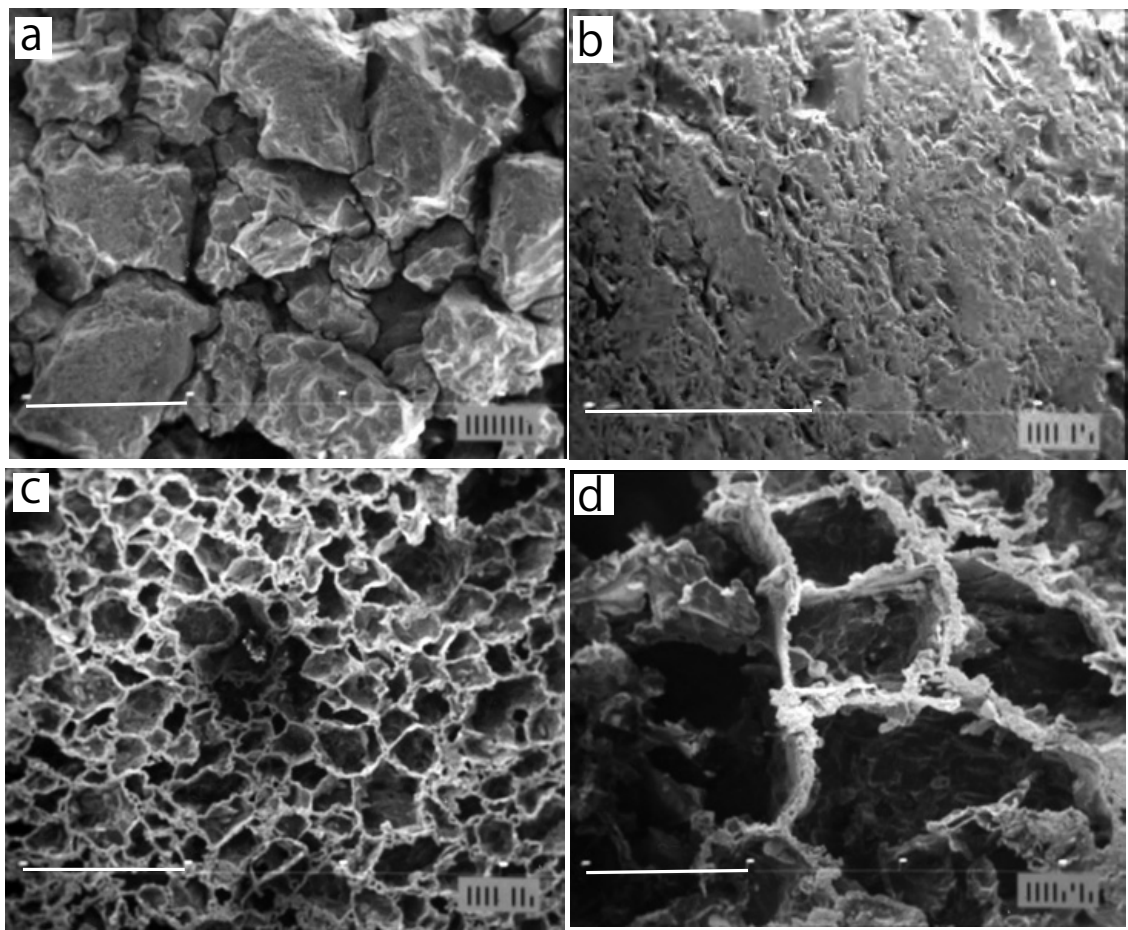

Figure 6. SEM images of itacolumites. Fractured surface of itacolumites (a) and cut surface of nonflexible quartzites (b) obtained from the Analabe locality (medium-grained). Skeleton of void space in itacolumites (c) and (d). (c) Analabe specimen (fine-grained). (d) Kiboy specimen (coarse-grained). Void spaces were impregnated with cyanoacrylate resin, and then, quartz grains were completely dissolved by hydrofluoric acid. Each scale bar is $1 \mathrm{~mm}$.

void-space content of the itacolumites is $16-19 \%$, which is two to four times that of the nonflexible quartzites.

The grain size of quartz is also shown in Table 1. The mean diameters of the Analabe, Vohibongo, and Kiboy specimens are about $0.2 \mathrm{~mm}, 0.4 \mathrm{~mm}$, and $1.2 \mathrm{~mm}$, respectively; the Kiboy specimen is mostly coarsegrained.

The fractured surface of the itacolumites and the cut surface of the nonflexible quartzites were observed under a SEM; these images can be observed in Figures 6a and $6 b$. The quartz grains of the itacolumites were clearly separated by narrow void spaces, whereas those of the nonflexible quartzites were not separated or only partly separated. For the visualization of void spaces, cyanoacrylate resin was injected into a small chip of the itacolumite specimen, and then, the chip was immersed in hydrofluoric acid (55\% dilute) for a few days until the quartz grains completely dissolved. The cyanoacrylate resin remained unaffected by hydrofluoric acid. Consequently, the remaining cyanoacrylate resin represented the skeleton of intergranular void spaces (Figs. 6c and 6d). Our study clearly shows that the void spaces of itacolumites form a three-dimensionally connected network.

The porosity of the Analabe itacolumite specimen was expediently determined by image analysis using the SEM image of the aforementioned cyanoacrylate skeleton. In this analysis, the total area of the void space was measured using the image analysis software "Win Roof" of Mitani Corporation, Japan (Fig. 7). The porosity determined from ten images ranged from $12 \%$ to $18 \%$, and the average value was $14 \%$.

A thin slab of the Analabe itacolumite specimen exhibited a considerable degree of flexibility under selfloading (Fig. 8)
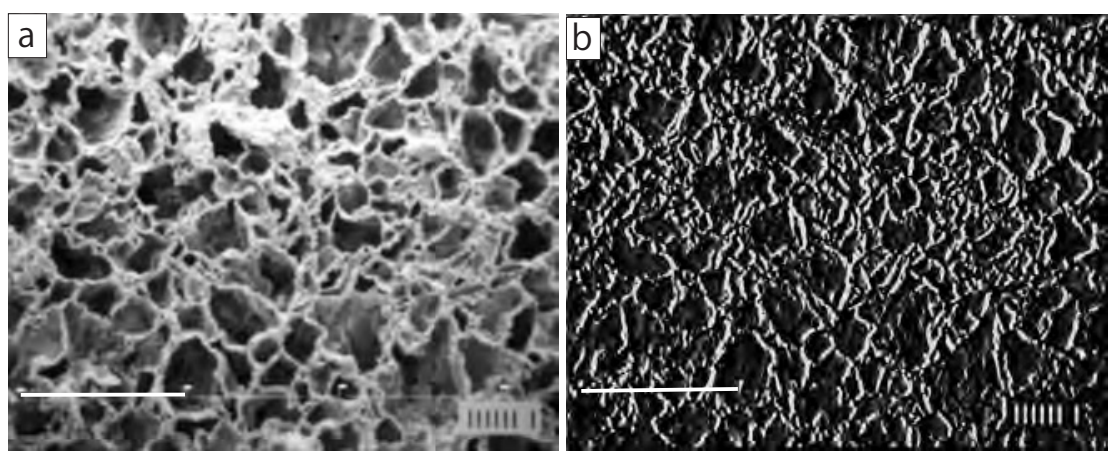

Figure 7. Digitized microscopic image of the skeleton of void spaces (a) and segmented image of void spaces after image processing (b). Fine-grained itacolumites of the Analabe locality. Each scale bar is 1 $\mathrm{mm}$. 


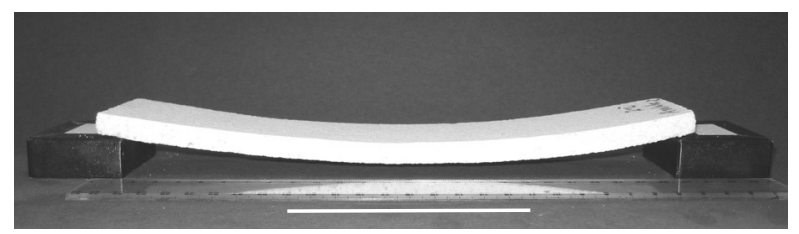

Figure 8. Flexibility shown by the Analabe itacolumite specimen under self-loading. The scale bar is $10 \mathrm{~cm}$. The specimen is 27.5 $\mathrm{cm}$ long, $6.5 \mathrm{~cm}$ wide, and $0.9 \mathrm{~cm}$ thick, and the midpoint deflection is $1.4 \mathrm{~cm}$.

\section{DISCUSSION}

\section{Itacolumites and nonflexible quartzites}

As shown in Table 1, point-counting of thin sections of the Analabe and Vohibongo specimens reveals that the quartz and muscovite contents of the itacolumites are lesser than those of the nonflexible quartzites, whereas the void space content of the former is two or four times greater than that of the latter. This fact suggests that the quartzite-to-itacolumite transformation is accompanied by the dissolution of quartz and muscovite, as shown by Suzuki and Shimizu (2003).

\section{Comparison of itacolumites from Madagascar, India, and Brazil}

Among the Madagascar itacolumites, the Analabe and Vohibongo specimens are quite similar to the Brazilian itacolumites in terms of mineral composition, grain size, and porosity. The Madagascar itacolumites are metamorphic quartzites, although the Brazilian itacolumites, which also contain kyanites, are high-grade metamorphic rocks. The Kiboy itacolumites specimen is unique as it contains very coarse-grained quartz. Lithologically, the itacolumites obtained from India are sedimentary quartzites and do not contain muscovite.

The highest porosity (18.8\%) is shown by the Kiboy specimen, and this value is the highest among those of the Brazilian, Indian, Appalachian, and Madagascar itacolumites (Table 2). This result suggests that the maximum porosity of itacolumites cannot exceed $20 \%$.

All the itacolumite specimens have been obtained from Proterozoic quartzites. The Brazilian and Indian quartzites are considered to be Paleoproterozoic, whereas the Appalachian quartzites are supposed to be Neoproterozoic (Suzuki and Shimizu, 1993, 2003). The Madagascar quartzites are considered Mesoproterozoic, as mentioned above.

\section{Significance of Madagascar itacolumites}

Two hypotheses have been proposed to explain the origin of the intergranular voids in itacolumites: chemical dissolution and mechanical separation. The former states that quartz grain boundaries and/or matrix minerals dissolve during the chemical weathering of nonflexible quartzites (Ginsburg and Lucas, 1949; Hawkins, 1951; Verma, 1982). The latter hypothesis insists on the mechanical separation of grain boundaries owing to thermal contraction at the time of metamorphism or during weathering (Carrozi, 1960; Devries and Jugle, 1968; Siegesmund et al., 2002). Suzuki (1996) has experimentally confirmed the greater likelihood of the former phenomenon, i.e., chemical dissolution of the quartz grain boundaries.

The discovery of Madagascar itacolumites provides new insights into the origin of itacolumites from two viewpoints. First, the occurrence of itacolumites in India, Brazil, and the Appalachians is restricted to thin layers within massive nonflexible quartzites that are mostly parallel to the bedding plane or the schistosity plane (Suzuki and Shimizu, 1993, 2003). However, in Madagascar, especially in the Analabe and Kiboy localities, itacolumites are commonly found over a wide area while nonflexible quartzites are very rare or absent. Such an occurrence strongly suggests that itacolumites are the product of weathering of nonflexible quartzites at or near the earth's surface.

Secondly, coarse-grained itacolumites such as the Kiboy specimen have not yet been reported. This implies that the formation of itacolumites is not directly related to the grain size of quartzites but is a function of the interlocking of quartz grains. However, a large grain size hinders such interlocking, resulting in the disintegration of the quartzites to quartz sand.

\section{ACKNOWLEDGMENT}

The authors sincerely thank Mr. T. Ishihara and Mrs. Y. Ishihara for their help during the field survey in Mt. Vo-

Table 2. Porosity of itacolumites and nonflexible quartzites

\begin{tabular}{cccc}
\hline & Itacolumites & Non-flexible quartzites & Reference \\
\hline Madagascar & $16.5,18.1,18.3,18.8$ & $5.0,9.7$ & This study \\
Brazil & $5.8,6.8,14.2,15.8$ & $4.6,5.1,6.2$ & Suzuki and Shimizu (2003, 2006) \\
Appalachia & $8.2,10.3$ & No specimen obtained & Suzuki and Shimizu (1993) \\
India & $15.2,17.3,18.6$ & $6.4,11.6$ & Suzuki and Shimizu (1993) \\
\hline
\end{tabular}


hibongo. They also express heartfelt thanks to Dr. M. Santosh of Kochi University, an anonymous referee, and the Associate Editor Dr. Fujimoto for providing helpful suggestions for the manuscript.

\section{REFERENCES}

Bate, R.L. and Jackson, J.A. Eds. (1987) Glossary of geology, 3rd ed. pp. 788, American Geological Institute, Virginia.

Bennison, A. (1989) Geological highway map of the Mid-Atlantic region. American Association of Petroleum Geologists, Tulsa, Oklahoma.

Collins, A.S., Kinny, P.D. and Razakamanana, T. (2011) Depositional age, provenance and metamorphic age of metasedimentary rocks from southern Madagascar. Gondwana Research, (in press) doi:10.1016/j.gr.2010.12.006

Carozzi, A.V. (1960) Microscopic Sedimentary Petrography. pp. 485, John Wiley, New York, 34-36.

Cox, R., Armstrong, R.A. and Ashwal, L.D. (1998) Sedimentology, geochronology and provenance of the Proterozoic Itremo Group, central Madagascar, and implications for pre-Gondwana paleogeography. Journal of Geological Society of London, 155, 1009-1024.

Devries, R.C. and Jugle, D.B. (1968) Structure-property relation in flexible sandstone. Journal of American Ceramic Society, $51,387-390$

Dorcieux, A., Stagnol, D., Huger, M., Chotard, T., Gault, C., Ota, T. and Hashimoto, S. (2008) Thermo-elastic behaviour of a natural quartzite: itacolumite. Journal of Material Sciences, $43,4167-4174$

Ginsburg, L. and Lucas, G. (1949) Presence de quartzites elastiques dans les gres armoricains metamorphiques de Berrien (Finistere). Comptes Rendus des Seances de L'academie des Sciences, 228, 1657-1658.

Hawkins, A.C. (1951) Flexible sandstone. Mineralogists, 19, 34.

Kerbey, H.C. (2011) Itacolumite, flexible sandstone and flexible quartzites- A review. Proceedings of the Geologists' Association, 122, 16-24.

Oliveira, A.I. (1956) Brazil. In Handbook of South American Geology (Jenks, W.F. Ed.). pp. 378, Memoires of Geological Society of America, 65, 1-62.

Rambeloson, R.A. (2004) Precambrian evolution of Madagascar Gondwana Research, 7, Supplementary Issue, 1375-1376.

Rambeloson, R.A., Yoshida, M., Ramasiarinoro, V., Le Duc, L. and Ralison, B. (2003) The Central Granites-Gneiss-Migmatite Belt (CGGMB) of Madagascar: the Eastern Neoproterozoic Suture of the East African Orogen. Gondwana Research, $6,641-651$

Santosh, M., Maruyama, S. and Sato, K. (2009) Anatomy of a Cambrian suture in Gondwana: Pacific-type orogeny in southern India? Gondwana Research, 16, 321-341.

Sato, I., Ichikawa, Y., Sakanoue, J., Mizutani, M., Adachi, N. and Ota, T. (2008) Flexible ceramics in the system $\mathrm{KZr}_{2}\left(\mathrm{PO}_{4}\right)_{3}{ }^{-}$ $\mathrm{KAlSi}_{2} \mathrm{O}_{6}$ prepared by mimicking the microstructure of itacolumite. Journal of American Ceramic Society, 91, 607-610.

Service Géologique de Madagasikara (1968) Carte Géologique Madagasikara 1/100,000 "Manandona". Centre de l'Institut Géographique National à Tananarive.

Shepard, C.U. (1845) On the occurrence of itacolumite and diamonds. Proceeding of Annual Meeting of Association of American Geologists and Naturalists, 6, 41-43.

Siegesmund, S., Bolibrecht, A. and Hulka, C. (2002) The anisotropy of itacolumite flexibility. In Natural Stone, Weathering Phenomena, Conservation Strategies and Case Studies (Siegesmund, S., Weiss, T. and Volbrecht, A. Eds.) pp. 496, Geological Society, London, Special Publication 205, 137-147.

Suzuki, H. (1996) Experimental study of the origin of intergranular void spaces in itacolumites. Science and Engineering Review of Doshisha University, 36, 185-202 (in Japanese with English abstract).

Suzuki, H. and Shimizu, D. (1993) Petrography of Indian, Brazilian and Appalachian itacolumites. Journal of Geological Society of Japan, 99, 391-401.

Suzuki, H., Yokoyama, T. and Nishihara, M. (1993) Scanning electron microscope and acoustic emission studies of itacolumites. Journal of Geological Society of Japan, 99, 443-456.

Suzuki, H. and Shimizu, D. (2003) Occurrence and porosity measurement of itacolumite newly found from Ouro Preto, Minas Gerais, Brazil. Science and Engineering Review of Doshisha University, 44, 1-12 (in Japanese with English abstract).

Tucker, R.D., Kusky, T.M., Buchwaldt, R. and Handke, M.J. (2007) Neoproterozoic nappes and superposed folding of the Itremo Group, west-central Madagascar. Gondwana Research, 12, 356-379.

Verma, V.K. (1982) Flexibility in itacolumites from Brazil, India and United States. Journal of Indian Association of Sedimentologists, 3, 19-28.

Yamaguchi, K., Matsufuji, Y. and Koyama, T. (2007) A new structural systems: friction-resistant dry-masonry. Building Research and Information, 35, 616-628.

Wadia, D.N. (1961) Geology of India, 3rd. ed. pp. 536, MacMillan, London.

Wetherill, C.M. (1867) Experiments on itacolumite, (articulite), with the explanation of its flexibility and its relation to the formation of the diamond. American Journal of Science, 44, 61-68.

Manuscript received December 10, 2010

Manuscript accepted September 28, 2011

Published online December 9, 2011

Manuscript handled by Koichiro Fujimoto 